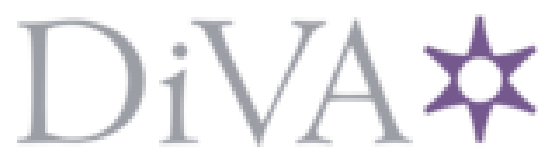

http://www.diva-portal.org

\title{
Postprint
}

This is the accepted version of a paper presented at CHI '12 Extended Abstracts on Human Factors in Computing Systems.

Citation for the original published paper:

Frey, B., Rosier, K., Southern, C., Romero, M. (2012)

From Texting App to Braille Literacy.

In: CHI '12 Extended Abstracts on Human Factors in Computing Systems (pp. 2495-2500).

Association for Computing Machinery (ACM)

CHI EA '12

http://dx.doi.org/10.1 145/2212776.2223825

N.B. When citing this work, cite the original published paper.

Permanent link to this version:

http://urn.kb.se/resolve?urn=urn:nbn:se:kth:diva- 184688 


\section{From Texting App to Braille Literacy}

\author{
Brian Frey \\ University of Maryland \\ Baltimore County \\ Department of Information \\ Systems \\ 1000 Hilltop Circle \\ Baltimore, MD 21250 \\ frey1@umbc.edu \\ Kate Rosier \\ Atlanta, GA \\ kady.rosier@gmail.com \\ Caleb Southern \\ Georgia Institute of Technology \\ School of Interactive Computing \\ 801 Atlantic Drive \\ Atlanta, GA 30332-0280 \\ caleb.southern8@gatech.edu

\section{Mario Romero} \\ Georgia Institute of Technology \\ School of Interactive Computing \\ 801 Atlantic Drive \\ Atlanta, GA 30332-0280 \\ mario@gatech.edu
}

\begin{abstract}
We report the results of a pilot study that explores potential uses for BrailleTouch in the instruction of braille literacy for the visually impaired. BrailleTouch is an eyes-free text entry application for smart phones.

We conducted individual semi-structured interviews and a focus group with four domain expert participants.
\end{abstract}

\section{Keywords}

Braille Literacy, Text Entry Applications, Touchscreens

\section{ACM Classification Keywords}

H.5.2. [Information Interfaces and Presentation]:

UI - Input devices and strategies, Voice I/O.

K.4.2. [Computers and Society]: Social issues -

assistive technologies for persons with disabilities.

\section{General Terms}

Design, Human Factors

\section{Introduction}

Maturing technologies such as optical character recognition, text-to-speech screen readers, and speech recognition are facilitating non-braille literacy for the visually impaired and may be playing a role in the declining numbers of braille literacy [10]. Nevertheless, most authorities in the visually impaired community hold braille literacy to be the most empowering form of literacy for low-vision and blind people. Not
Copyright is held by the author/owner(s).

CHI 2012, May 5-10, 2012, Austin, TX, USA.

ACM $x x x-x-x x x x-x x x x-x / x x / x x$. 


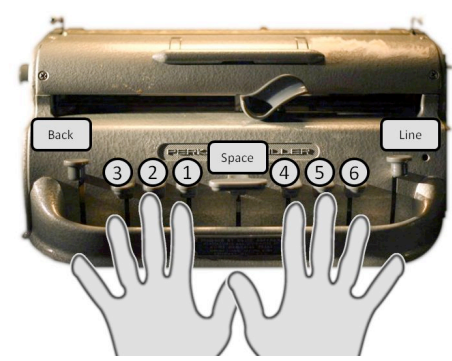

Figure 1: A typical braille keyboard is a $1 \times 6$ array of keys that chords up to 63 characters. The Perkins Brailler above has a few extra keys for space, backspace, and line feed.

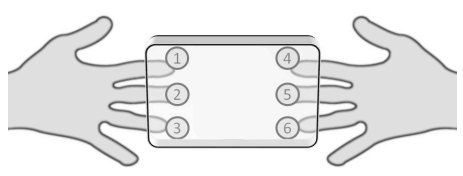

Figure 2: BrailleTouch folds the $1 \times 6$ array into a $3 \times 2$ keyboard and faces the screen away from the user (a see-through device).

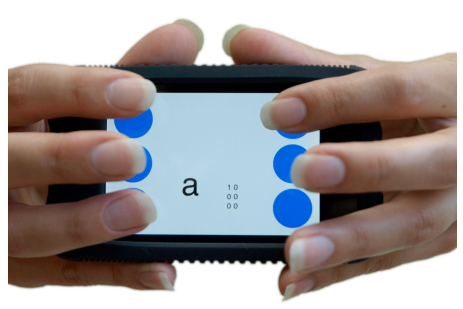

Figure 3: User typing "a" with BrailleTouch on the Apple iPod Touch. Gestures replace the extra keys for space (rightswipe), backspace (left-swipe), and enter (double right-swipe). surprisingly, Ryles demonstrated that among congenitally visually impaired adults, learning to read braille as a child is the strongest predictor of higher levels of education and employment in adult life [10]. The heart of our proposal is to use technology to support braille literacy rather than supplant it.

BrailleTouch is an eyes-free text-entry application for multi-touch smart phones [4]. It maps typical braille chorded typing onto the phone's pocket-sized screen by folding the standard $1 \times 6$ keyboard into a $3 \times 2$ keyboard (see Figures 1, 2, and 3). BrailleTouch's ergonomic grip faces the screen away from the user. This feature turns the phone into a "see-through device" that maps exactly the $3 \times 2$ braille cell, making it a spatial mnemonic for braille. As Sandnes showed, people easily learn the mapping between a chord and a letter [11].

Previously, we conducted a pilot study with six participants, two of whom were braille instructors [4]. One of the instructors commented that she would like to use the prototype as a teaching device. This observation motivated the present study. We recruited four professional braille instructors, individually presented them with BrailleTouch, conducted semistructured interviews, and concluded with a focus group with three of the participants.

\section{Research Questions}

Our goal is to propose an inexpensive alternative to the devices typically used in promoting braille literacy. Our research questions aiming at this goal are:

RQ1. What is the real-life state of braille instruction, especially with respect to interactive technologies?

RQ2. How do professional braille instructors teach braille literacy to the visually impaired?
RQ3. What are the major challenges in promoting braille literacy?

RQ4. Can BrailleTouch become an instruction tool and give support to overcome some of those challenges and if so, how?

\section{Related Work}

Kane explored the challenges in gesture-based touch screen input for the visually impaired and suggested guidelines for designing these interfaces [6]. Table 1 shows the full compatibility match between

BrailleTouch's features and Kane's guidelines.

\begin{tabular}{|l|l|}
\hline $\begin{array}{l}\text { Accessible Touchscreen } \\
\text { Guidelines [6] }\end{array}$ & \multicolumn{1}{c|}{$\begin{array}{c}\text { BrailleTouch's } \\
\text { Compatibility }\end{array}$} \\
\hline $\begin{array}{l}\text { Avoid symbols used in } \\
\text { print writing. }\end{array}$ & $\begin{array}{l}\text { No symbols, only chorded } \\
\text { taps and swipes. }\end{array}$ \\
\hline $\begin{array}{l}\text { Favor edges, corners and } \\
\text { other landmarks. }\end{array}$ & $\begin{array}{l}\text { The shapes of the phone } \\
\text { and screen act as guides. }\end{array}$ \\
\hline $\begin{array}{l}\text { Reduce demand for } \\
\text { location accuracy. }\end{array}$ & $\begin{array}{l}\text { Target locations are large } \\
\text { and flexible. }\end{array}$ \\
\hline $\begin{array}{l}\text { Limit time-based gesture } \\
\text { processing. }\end{array}$ & $\begin{array}{l}\text { No time-based processing. } \\
\text { Input at all-fingers lifted. }\end{array}$ \\
\hline $\begin{array}{l}\text { Reproduce traditional } \\
\text { spatial layouts when } \\
\text { possible. }\end{array}$ & $\begin{array}{l}\text { Traditional braillewriter } \\
\text { layout rotated 90-degrees. } \\
\text { Finger to key map intact. }\end{array}$ \\
\hline
\end{tabular}

Table 1: BrailleTouch's design vs. guidelines in [6].

We view one of BrailleTouch's roles in literacy as that of external reinforcement (something that happens outside of the classroom). Both Craig and Brennan examined the impact of external reinforcement of braille on literacy $[2,3]$. Craig said, "Overall, the results showed that the braille readers did not engage in as many literacy activities per week as did the print readers." Brennan et al. report that parents who were 


\section{List 1: Survey}

1. What is your age?

2. What is your gender?

3. Are you right or left

handed?

4. What is your occupation?

5. What is your current level of vision?

6. Since what age have you

had your current level of vision?

7. At what age did you learn braille?

8. Please list the devices you own, use or teach braille with.

9. How long have you taught braille?

10. How many students do you currently work with?

11. How large are class sizes?

12. What age group do you

primarily work with?

13. How often do you

administer tests?

14. What kinds of tests do you administer?

15. In your classroom, is there a difference in importance

between braille writing speed

and braille writing accuracy? If

so, which is more important? fluent in braille had a positive influence on their child's ability to read braille. We consider that BrailleTouch, a mobile app, could promote reinforcement outside of the classroom because of its portability and ubiquity.

Rosenblum interviewed university instructors who had taught braille literacy courses. She found

inconsistencies in how students were taught, which she connected to a lack of a state or national assessment. Her work influenced this study's survey.

\begin{tabular}{|l|c|c|l|l|}
\hline & Age & Gender & Experience & Vision \\
\hline P1 & 34 & F & 9 Years & Sighted \\
\hline P2 & 36 & F & $1 \frac{1}{2}$ Years & V.I. \\
\hline P3 & 36 & F & $11 \frac{1}{2}$ Years & Sighted \\
\hline P4 & 28 & F & 1 year & Sighted \\
\hline
\end{tabular}

Table 2: Relevant demographics of the participants.

\section{Study Design}

We designed a qualitative pilot study. We recruited four professional braille instructors at the local center for the visually impaired. We did not compensate them. Table 2 summarizes relevant demographics. We collected their experiences and perspectives on teaching literacy to the visually impaired through an entry survey (see List 1) and a semi-structured interview (see List 2) with BrailleTouch in their hands. We trained them to use BrailleTouch and we conducted a ten-minute exercise. Our goal was to simulate operation under stress to deepen their perspectives of BrailleTouch's affordances and limitations. We concluded with a focus group with three participants (one dropped out). During our study we took field notes, recorded interviews and transcribed these interviews. We coded the data for phrases that reflect how the participants teach literacy and, specifically, how they use technology to support their practices. For the same questions, we coded similar and dissimilar phrases between the participants. We compared these findings to our research questions.

\section{Braille for Real Life}

Although from our perspective we recruited professional braille instructors, the teachers made a point to say they were more than that. They emphasized their title to be "Teacher for the Visually Impaired". They exposed a broader perspective of the demands for educating visually impaired children. All participants focus on realworld practical knowledge. They teach braille literacy as well as way finding, colors, shapes, and even toileting.

External Reinforcements for Learning Braille All participants emphasized the importance of braille exposure for the students outside of the classroom. P2 has students come to her classroom for reading each day between the end of class and the arrival of transportation.

\section{Age Appropriateness}

All participants felt that children needed exposure to braille as early as possible; age three was the most common answer, except for P2:

I believe they need to be introduced to it from birth. [...] The way that I introduce Braille to an infant or toddler is [similar to] how you would introduce print reading to [a sighted] child. You put their hands on it so they're exposed to understanding tactility and exploring things. Braille is a tactile skill so you encourage them at an early age to use their hands to explore and gather 


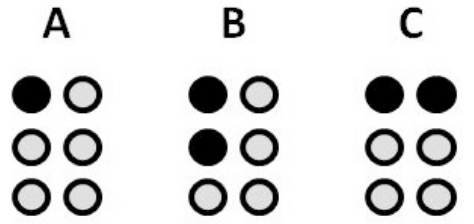

Figure 4: Grade 1 braille (uncontracted) maps one and only one binary combination of the braille cell to one and only one alphanumeric character.

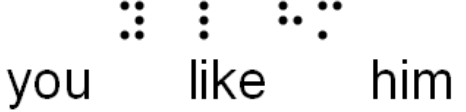

Figure 5: Grade 2 braille (contracted) maps one or more binary combinations of the braille cell to entire words or phrases. Contracted braille is defined by a formal grammar.

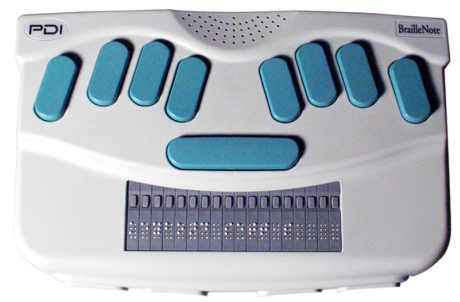

Figure 6: The HumanWare BrailleNote $(\$ 1600)$ is one of the preferred computers for persons with visual impairments. Its use is similar to a PDA's. It includes a refreshable braille display. information. [I] play with rice to decrease their tactile defensiveness.

\section{Tactile Defensiveness}

Nielsen defines tactile defensiveness in the visually impaired as a tendency to be alarmed to tactile input which is generally considered harmless [8]. Tactile defensiveness can initially stem from guiding exploration by manipulating the explorer's hands. It can be met with resistance, even in infants, because it is potentially disrupting their cognitive processes. P2 explained tactile defensiveness as:

You [the interviewer] are not blind. You get information from seeing and decide if you want to touch. [If] a child cannot see, [he or she does not] know what they're touching. They are sensitive to different textures. You want to decrease that sensitivity by letting them explore other textures.

\section{Starting with Grade 1 or Grade 2 Braille}

There are two major encodings of English braille: Grade 1 (uncontracted) braille; and Grade 2 (contracted) braille [1]. Grade 1 braille holds a one-to-one correspondence between each chord and an alphanumeric character (see Figure 4). Grade 2 braille encodes entire words into a sequence of one, two, or three braille chords (see Figure 5). Grade 2 braille's abbreviations encode meaning through context.

By exploring the preference for the grade of braille, the prototype could be modified to meet these needs. Hong found no difference in reading ability between children who were introduced to braille with grade one or grade two [5]. Three participants felt children should be started with grade two, with special attention placed on spelling and grammar. But P1, the instructor with the most experience, felt differently: "If they do not know the code well enough to write sentences like a fifth or sixth grader, then I don't push grade two on them."

The differences in opinion may be due to what Hong's research suggests. The most experienced participant had been an instructor for several years when Hong released his publication and the others received their training several years afterwards.

Teaching braille to children with low-vision There was also strong consensus on the importance of teaching braille to children with low-vision. While all participants saw the value, the visually impaired nstructor described it as her "passion". She went on to reference statistics on literacy and linked illiteracy to unemployment. Upon further discussion she noted she was utilizing the work of Dr. Ruby Ryles [10].

All participants felt an early exposure to braille, even if the child was low vision, was very important. They carefully observed the children's spelling after introducing contracted braille.

\section{Teaching Braille}

We explored the participants' challenges and preferred devices for teaching braille.

Preferred Device for Teaching Braille

The HumanWare BrailleNote is a portable braille input and output device functionally similar to a PDA (see Figure 6). The instructors value its compactness, low weight, ability to keep files and provide audio feedback P2: "The kids [that are] having difficulty with accuracy like the audio feedback. [They] can go back, make 


\section{List 2: Interview}

1. When you learned braille, where did you learn and what tools did they use?

2. Of the devices you own, use or teach braille with, which one is your favorite?

3. Of the devices you own, use or teach braille with, which one is your LEAST favorite?

4. If I wanted to become an instructor for the visually impaired, how would I do it? 5. In what type of places have you taught braille (prompt if necessary: at a rehabilitation center, at a school for the visually impaired, as an itinerant instructor, etc.) and to what groups (children, adults, etc)? 6. How were the experiences different from each other? (Only ask if applicable)

7. What are the major challenges in teaching braille?

8. How do you overcome those challenges?

9. What steps would you go through to teach me braille?

10. Please describe your classes and their makeup.

11. How do you evaluate your student's progress?

12. What happens if you feel their progress needs improvement?

13. How do you determine the appropriate age to introduce children to braille? corrections and hear what they've entered. The ones who have reversal issues can get the feedback, can go back instantaneously, and make the correction." She later clarified "reversal issues" occurred when a child is taught the embossed shape instead of the dot location and flips, rotates, or reverses them.

\section{Challenges in Teaching Braille}

Participants provided practical and philosophical challenges. P1 and P3 voiced concerns about having enough material to teach and keep current with braille pedagogy. P2 and P4 expressed concern about the physical and social perceptions of students.

P4 felt challenged for being sighted. She referred to a need for a "non-visual perception of [her] instructions". She believes that low-vision children should learn braille by using sleep shades. She spent up to eight hours a day in graduate school wearing these shades and continues to use them while she teaches.

P2 strives to overcome attitudes that braille is overly complex and unnecessary. She feels this attitude comes from general-education faculty, parents, and the students themselves, who get messages that "it is no longer needed". She feels that lacking external reinforcement is detrimental to literacy, similar to [2].

Participants regularly substituted "teaching braille" with "literacy", implying no functional differences between raised dots and inked glyphs. Communication technologies constantly translate codes. Devices like BrailleNote serve pedagogic roles bridging the gap between chords, phonemes, and bumps.

\section{BrailleTouch as an Instruction Tool}

Teachers of people with disabilities face typical and special challenges. Participants interacted with BrailleTouch and expressed their opinion about it as a teaching device, focusing on their special challenges. All participants immediately devised multiple uses. For example, P4:

You could use it for quizzes, tests, mastery of certain contractions; use it because of the feedback. It's really cool! [...] It's a self-check too. They can go to a list. 'Hey can you spell the word bird?' and then they just do it. [...] it would really reinforce the dot locations and that is crucial to learning braille.

The strongest support came from the only visually impaired participant. P2 felt she could use BrailleTouch as a tool for instruction. She also wanted BrailleTouch for her low-vision daughter and kindly requested the app for her phone as soon as possible.

P3 felt the device could involve parents. She suggested: "I could bring my personal iPod Touch and let the kids use it. Other teachers don't have one, but a lot of the parents have an iPod, iPhone, and iPad."

Additional Uses for BrailleTouch raised at Focus Group One focus group discussion focused on porting BrailleTouch to other touch screen devices, e.g. the iPad. Their district is taking steps to put iPads in classrooms. Participants discussed the functionality of the devices, e.g. connectivity. One participant was excited about connecting these devices to their embosser. The discussion moved to a recent innovation from Northeastern University, Retrofitted Braille 
List 2: Interview- cont

14. What are your feelings about starting young children off with either grade 1 or grade 2 braille?

15. How do you feel about teaching braille to children with low vision?

16. How do you create a lesson plan?

17. Let's take a few minutes and go through the steps to create a lesson plan. (Only ask if applicable)

18. Please describe the tests you use.

19. What is the difference between the importance of braille writing accuracy and braille writing speed, in your classroom? (Only ask if applicable)

20. Do you feel you can use BrailleTouch to teach braille; if so, specifically how?

21. Do you feel any of the groups you work with would benefit more or less than any other group from instruction with BrailleTouch (prompt if necessary: very young children, adults who have recently lost their vision, etc)?
Embosser to an Inkjet Printer [7]. At this point, P2 had the idea to use BrailleTouch "instead of paying $\$ 3000$ for another piece of equipment." The moderator asked, "To clarify, you feel this would be a replacement for most of the electronic devices you use?" P2: "Yes".

\section{Conclusions and Future Work}

We studied how a small sample of teachers promotes braille literacy. After handling BrailleTouch, all the participants had a collection of ideas about how to use it to promote literacy, replacing adequate but expensive tools in their classroom and promoting parent external reinforcement of their children's literacy skills.

\section{Future Work}

Participants suggested: 1 ) adding a screen protector with raised dot landmarks; 2 ) augmenting the prototype with Grade 2 braille; 3) including different permissions to limit the amount of functionality available, for applications such as a spell checker, a web browser, and a calculator; and 4) adding the ability to change the sensitivity of the touchscreen, especially to reduce it for newer users.

Our next step is to run a deployment study at a school for the visually impaired. We feel a longitudinal, in-situ, between-subject study measuring literacy improvements will reveal many opportunities and challenges for interactive technologies.

\section{Citations}

[1] Braille Authority of North America, English Braille, American Edition American Printing House for the Blind (2004).

[2] Brennan, S., Luze, G., and Peterson, C., Parents perceptions of professional support for the emergent literacy of young children with visual impairments Journal of Visual Impairment and Blindness,

Oct/Nov2009, Vol. 103 Issue 10, (2009) 694-704.

[3] Craig, C. Family support of the emergent literacy of children with visual impairments. Journal of Visual Impairment and Blindness, 90, (1996) 194-200.

[4] Frey, B., Southern, C., and Romero, M., BrailleTouch: Mobile Texting for the Visually Impaired, in Universal Access in Human-Computer Interaction. Context Diversity, C. Stephanidis, Editor. Springer Berlin / Heidelberg (2011), 19-25.

[5] Hong, S. and Erin, J., The Impact of Early Exposure to Uncontracted Braille Reading on Students with Visual Impairments. Journal of Visual Impairment and Blindness, 98, (2004) 325-340.

[6] Kane, S., Wobbrock, J., and Ladner, R., Usable Gestures for Blind People: Understanding Preference and Performance, in CHI '11 (2011) 413-422.

[7] Kornwitz, J., Engineering students win innovation prize. News@Northeastern. Paper (2010) 701

[8] Nielsen, L., Guiding Hands: Help or Hindrance? How the Approach of Guiding the Hands of the Visually Impaired Child Can Disturb His Opportunity to Build-up Strategies for Tactile Orientation. National Braille Press, Future Reflections, Vol. 14 No. 3 (1995).

[9] Rosenblum, L., Lewis, S., D'Andrea, F., Current Practices in Instruction in the Literary Braille Code: University Personnel Preparation Programs. Journal of Visual Impairment and Blindness, 104.9 (2010) 523532

[10] Ryles, R. Braille as a predictor of success. In J. M. Dixon (Ed.), Braille into the next millennium.

Washington, DC: National Library Service for the Blind and Physically Handicapped and Friends of Libraries for Blind and Physically Handicapped Individuals in North America. (2000). pp. 463-491.

[11] Sandnes, F. Can spatial mnemonics accelerate the learning of text input chords?, AVI '06 (2006) 245-249. 